\title{
Shcharanskii trial stirs new anti-Soviet protests
}

ScIENTIFIC and technological cooperation should not be linked to questions of human rights and the implementation of the Helsinki accords, according to a Tass statement issued last month in the aftermath of the Orlov trial. This sentiment is clearly not reciprocated abroad. The trial of Anatolii Shcharanskii, cyberneticist and human rights campaigner, this week has already evoked a wave of protest.

More than 200 French scientists are petitioning for a boycott of scientific contacts with the Soviet Union, in protest against the sentence on Yurii Orlov, while two high level American visits by Dr Frank Press, President Carter's scientific adviser, and Barbara Blum, deputy administrator of the Environmental Protection Agency to the Soviet Union have been cancelled because of the Shcharanskii trial.

The Soviet Union is clearly extremely sensitive to the cancellation of such scientific contacts. One of the charges made against Shcharanskii in the Soviet press at the time of his arrest last year was that he had been working towards the disruption of scientific detente. Describing the alleged espionage activities of Shcharanskii and his associates in the human rights movement, Izvestiya stated: "A letter from Rubin arrived August 1976 through unofficial channels via the American correspondent Osnos. It requested a quicker forwarding of this information so as to start a campaign to put a ban on the sale of American equipment to the USSR."

According to his accusers, therefore, Shcharanskii was not simply guilty of espionage: his offence was exacerbated by being directed against the development of scientific and technical exchange. It would be ironic, indeed, if his trial resulted in a complete or partial breakdown of such contacts.

However, a complete boycott of all scientific exchange seems unlikely-if only for the pragmatic reason that, if the ultimate weapon is unsuccessfully deployed, there are no further bargaining resources.

Dr Robert W. Kates, chairman of the Committee for Human Rights of the US National Academy of Sciences, stresses the "remarkable response on the part of the American scientific community" in defence of human rights activists such as Orlov and Shcharanskii. Already, he said, there had been many voluntary and individual acts of conscience. He further noted that while scientific exchanges can be agreed at official levels, participation in them is voluntary. "Science is a voluntary activity".

$\mathrm{He}$ feared that, as a result of the Shcharanskii trial, "there will be a deep and persistent sense of disillusion" among scientists. This would continue unless there was "some sign of a judicious and humanitarian response by the Soviet authorities".

\section{It's all in the mind ...}

Academician Andrei Snezhevskii, Director of the Institute of Psychiatry of the Academy of Medical Sciences of the USSR has become well-known of recent years in the western pressnot the least for his remarkable discovery of "sluggish" or "creeping" schizophrenia-a mental disorder which presents no clinical symptoms.

Not surprisingly, western specialists have become intrigued by this illness, which seems confined entirely to the Soviet Union-where however, it seems endemic among a certain section of society.

For, in particular "sluggish" schizophrenia (a subdivision of "continuous") is a particularly powerful concept in Soviet forensic psychiatry. It is, in the words of one prominent Soviet psychiatrist, "schizophrenia without schizophrenia". It is expressed only in certain behaviour patterns, showing "poor adaptation to the social environment". In a handful of cases, this has been invoked for such deviations as a hippy-like mode of dress. The typical "sluggish schizophrenic", however, exhibits "paranoid delusions of reforming society"-or dissidence and a concern with human rights.

Last week, Dr Ilya Glezer, a former member of the staff of Snezhnevskii's institute, who is now working at the University of Beersheva (Israel) visited London, providing an opportunity for Nature to learn more of Snezhnevskii's principles of diagnosis.

Dr Glezer is himself not a psychiatrist but a neurocytologist. In general,
Soviet psychiatry stresses the physical and genetic background of disorders and de-emphasises the environmental factors. As part of his post-doctoral research, Dr Glezer was to prepare a survey of post-mortem brain analyses of deceased psychiatric patients.

On commencing his research he was instructed to pay great attention to the case-histories of the patients. Accordingly, he delivered the casenotes to a team of close associates and pupils of Academician Snezhnevskii, who pencilled on each the diagnosis according to the director's scheme "continuous schizophrenia", "periodic schizophrenia", "shift-like schizophrenia". (It should be noted that to Snezhnevskii, all mental disorder can be classified as a form of schizophrenia.)

After completing his investigation of some fifty cases Dr Glezer was ready to present his findings. Again he was told to check up on the case-histories. Some time having elapsed since the first classification was made, he carefully rubbed out the first set of diagnoses, and returned the notes to Snezhnevskii's team. Later the notes came back-with different diagnoses.

Since the patients concerned were all dead, Dr Glezer found himself unable to explain this phenomenonexcept on the assumption that the various types of schizophrenia of Shezhnevskii's system do not correspond to any defined clinical pattern, but are assigned more or less arbitrarily. (Since the "diagnoses" were made by

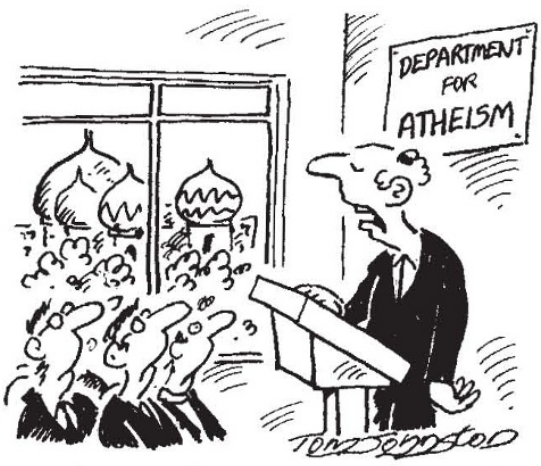

"And remember, comrades, illness after death does not prove life after death"

some of Snezhnevskii's closest associates, one can hardly impute to them incompetence in applying Snezhnevskii's criteria).

In due course, Dr Glezer was dismissed from the institute and later sentenced to three years in prison and three years exile, on the charge of slandering the State. The formal evidence against him was the writing of letters to government and Party officials in support of the Jewish emigration movement.

Dr Glezer readily admits writing such letters. However, many other Jewish activists and would-be emigrants have written similar letterswithout incurring such harsh sentences. The suspicion inevitably arises that he was jailed not only for the letters but also of his exposure of the arbitrary nature of Snezhnevskiitype diagnosis.

Vera Rich 